\title{
MULHERES NA POLÍTICA NO ESTADO DO PARÁ, REGIÃO NORTE BRASILEIRA
}

\author{
Women in Politics in the State of Pará, Brazilian North Region
}

Juliana Rodrigues Freitas

Laís Vieira Guimarães

Resumo: Um dos pressupostos da democracia ao lado da representatividade é a pluralidade, que numa sociedade marcada pela hegemonia de um grupo dominante nos espaços públicos, políticos e de tomadas de decisão torna-se de difícil alcance, impondo a necessidade de rompimento de um status quo opressor e excludente, para que, então, possa ser configurada. A Região Norte do Brasil é caracterizada por inquestionáveis riquezas naturais que convivem num cenário de altos índices de carência de política pública. O debate acerca da representatividade e pluralidade na política, no Estado do Pará, sob a perspectiva de gênero, apresenta um panorama que não difere dos outros estados brasileiros, mas ganha maior relevância por essa ausência de políticas públicas. Temos um cenário, então, em termos quantitativos, de poucas mulheres no espaço político e dessas, um número ainda mais limitado defensor das pautas feministas capazes que são de minimizar o histórico de desigualdades abissais em nossa sociedade. Além disso, identifica-se que quando, escassamente, essa pauta é defendida no legislativo, o executivo com ele não dialoga, aprofundando as amarras que impedem a igualdade de gênero e o consequente respeito aos direitos das mulheres no nosso sistema.

Palavras-chave: Igualdade de gênero. Mulheres. Representatividade. Política. Feminismo. Pará.

\begin{abstract}
Alongside representativeness, another assumption of democracy is plurality, which in a society marked by dominant groups in public, political, and decision-making spaces is difficult to reach. It is, therefore, crucial to break the oppressive and excluding status quo. The northern region of Brazil is characterized by unquestionable natural wealth that coexists in a scenario of severe public policy deficiency. In the state of Pará, the debate about representativeness and plurality in politics, from a gender perspective, is inserted in a context similar to other Brazilian states but aggravated due to the absence of public policies. There are few women in the political space, and not many advocate feminist agendas to minimize the history of abysmal gender inequality in society. In addition, when this agenda is (rarely) defended in the legislative branch, the executive fails to establish a dialogue, jeopardizing gender equality and the consequent respect for women's rights in the system.
\end{abstract}

Keywords: Gender equality. Women. Representativeness. Politics. Feminism. Pará.

Artigo recebido em 17 out. 2020 e aprovado em 15 nov. 2020. 


\section{Introdução}

Uma das possibilidades para o aumento da participação feminina, respeitando a autonomia partidária resguardada em nossa Constituição Federal (art. 17), implica em reconhecer à base partidária o seu poder de decisão dos nomes aptos para lhe representarem nas eleições, exatamente, nos termos mais genuínos das convenções partidárias, que longe de serem meras formalizações das escolhas da cúpula partidária, devem representar uma reunião democrática em que todos os filiados e as filiadas escolhem e depositam a sua confiança naqueles (as) mais envolvidos(as) com os ideais e compromissos partidários.

Afinal, uma sociedade que tem enraizada a desigualdade de gênero, numa cultura patriarcal opressora, é marcada pela discriminação em toda a sua estrutura de poder (econômica, social, cultural, educacional, étnica/ racial), e a subsequente monopolização das políticas, que, ao invés de públicas, tornam-se particulares atendendo aos interesses de uma minoria hegemônica que ocupa os espaços nas distintas esferas de poder, contrariando os axiomas da pluralidade, representatividade e alternância que deveriam nortear os princípios democráticos.

O déficit de representação das mulheres é um problema que vem desde a Antiguidade, onde sequer eram consideradas cidadãs, e para os dias de hoje, com a conquista do direito ao voto e de se candidatar, é de se imaginar que muitas dessas barreiras foram ultrapassadas no âmbito político e social; entretanto, ao observar as relações de gênero nos distintos segmentos que integram as estruturas da sociedade, evidencia-se a existência de obstáculos que dificultam o ingresso da mulher na política, tornando-se barreiras cada vez mais difíceis de serem enfrentadas, inclusive consideradas as várias interseccionalidades que se apresentam (raça, classe, etnia/ raça, sexualidade), tornando a mulher cada vez mais em desvantagem na sociedade (PINHEIRO, 2018, p.119).

Simone de Beauvoir (1980, p. 14-23), na introdução de seu livro $O$ Segundo Sexo, afirma que no caso das mulheres, diferente de outros grupos marginalizados, suas ações nunca passaram de uma agitação simbólica, ou seja, só ganharam aquilo que lhes foi concedido pelos homens, por motivos tanto da ausência do sentimento de comunidade entre elas, quanto pelo fato da sua subordinação a eles não ter acontecido a partir de um fato histórico, porque sempre existiu; o que dificulta o processo de libertação das mulheres dessas amarras. 
Nascemos em uma sociedade que nos agrega senso comum, isto é, um conhecimento adquirido e disseminado a partir do que socialmente é entendido como certo ou errado, e padrões de comportamentos a serem seguidos por homens ou mulheres, estabelecidos, inclusive, pelos próprios homens às mulheres, ferindo de morte a igualdade de gênero prevista em

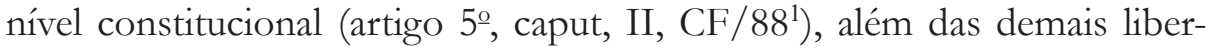
dades que devem nos ser garantidas, e protegidas. O machismo estrutural traz consigo falas, opiniões e ações, que são (re) produzidas como regras numa padronização de comportamento de acordo com as quais a mulher é silenciada, ignorada e subestimada, numa relação de constante opressão.

A escritora feminista nigeriana, Chimamanda Ngozi Adichie, em seu discurso no TED x Euston, que mais tarde se tornou um livro, relembrou que aos 9 anos de idade sonhava em ser monitora de turma quando a professora propôs que aquele aluno que obtivesse a maior nota no teste ocuparia o cargo. Entretanto, mesmo tendo conquistado a maior nota da sala, a professora deu o título de monitor ao menino que ficou em segundo lugar por considerar óbvio o pré-requisito para o exercício de aquela função ser do sexo masculino (ADICHIE, 2015, p. 15-17).

Esse exemplo destaca como a mulher não é vista como apta a exercer cargos de poder, seja de presidente da República ou monitora de uma classe de ensino fundamental, apenas pelo receio de interromper o status quo, que considera o homem como o único capacitado a exercer um papel de liderança, ou de comando nas esferas públicas e particulares, mesmo quando a mulher se mostra mais qualificada, o que reiteradamente ocorre. Chimamanda destaca que a repetição de certas crenças por meio de falas e ações faz com que as aceitemos como normais, apesar de, tão somente, comuns numa sociedade preconceituosa construída sob um cenário de injustiças. (2015, p. 16-17).

Especificamente no caso da política, é necessário desmistificar a ideia de que não se trata de um lugar para ser ocupado por mulheres, quando, em especial, é por meio desta, e porque implica em administração do poder, que existe a possibilidade de mudança de um status quo desfavorável à satisfação dos interesses públicos e proteção dos direitos das minorias. Para

\footnotetext{
${ }^{1}$ Art. 5o Todos são iguais perante a lei, sem distinção de qualquer natureza, garantindo-se aos brasileiros e aos estrangeiros residentes no País a inviolabilidade do direito à vida, à liberdade, à igualdade, à segurança e à propriedade, nos termos seguintes: I - homens e mulheres são iguais em direitos e obrigações, nos termos desta Constituição.
} 
a cientista Flávia Biroli, o principal problema dessa pauta é o fato de que "a política é atualizada como espaço masculino”, visto que o espaço público e as instituições políticas excluem e marginalizam as mulheres e outros grupos sociais subalternizados (BIROLI, 2018, p. 172).

O interesse por política deve ser social e estruturalmente estimulado, especialmente numa sociedade não binária, vez que ainda, quando não queremos seguir carreiras políticas, é nosso dever, enquanto cidadãos e cidadãs, exercermos o direito de voto, o que implica em consciência, engajamento e educação política, para que o voto não seja uma mera obrigatoriedade pro forma a ser cumprida sem responsabilidade coletiva.

É imprescindível para a solidificação da democracia a criação de um cenário político em que as mulheres se sintam dele pertencentes e atuem como protagonistas no uso dos instrumentos capazes de lhes proporcionar melhorias na qualidade de vida por meio de políticas públicas e, assim, diminuir os impactos nefastos dos abismos provocados pela desigualdade que nos assola, seja pelo voto em uma candidata que defenda a pauta da igualdade de gênero, ou como eleita para ocupar um cargo político, possibilitando a concretização desses interesses.

A luta pela igualdade de gênero é pauta central da agenda do movimento feminista que, ainda que tenha tido sua primeira onda com o movimento das sufragistas, entre o fim do século XIX e o início do século XX, o movimento ganha força maior a partir dos anos 1970 quando debates e ações colocam em destaque a posição vulnerável na qual a mulher está inserida na sociedade, e se une para transformar o sistema e combater o patriarcado.

Considerando o fortalecimento da discussão relativa à igualdade de gênero no âmbito político, realizaremos, então, um desenho legislativo das políticas de incentivo adotadas no Brasil para o aumento da participação da mulher no cenário político.

O direito à igualdade em um país como o Brasil, que tem como regime político a democracia representativa, impõe como essencial a qualquer projeto democrático, a igualdade no exercício dos direitos civis, políticos, econômicos, sociais e culturais, e, acima de tudo, o exercício, em igualdade de condições, dos direitos humanos elementares. (PIOVESAN, 2006, p. 36-43) 
Com o subsídio da análise de dados, identificaremos a eleição das mulheres entre os anos de 2009 e 2019, para a composição das Assembleias Legislativas do Estado do Pará, da Região Norte do Brasil, e os impactos dessa representatividade na produção legislativa em favor das mulheres, bem como quais os partidos que elegeram mais mulheres, em nível estadual, nessa região brasileira.

\section{Medidas de incentivo à participação das mulheres na política adotada em nível estadual}

Anterior à previsão federal do voto feminino, ainda em 1927, o Estado do Rio Grande do Norte foi o primeiro a conceder às mulheres o direito ao voto, e um ano depois elegeu a primeira prefeita da América Latina com 60\% (sessenta por cento) dos votos, chamada Alzira Soriano, que teve o seu mandato interrompido pelo golpe de 1930, sendo convidada pelo então presidente Getúlio Vargas, a permanecer no cargo como interventora municipal, mas se e recusou por entender o cargo como incompatível com os seus ideais democráticos. Voltou a participar de forma ativa da política após a redemocratização, elegendo-se vereadora algumas vezes. (SCHUMAHER, 2015, p. 65-66)

A partir da instituição do Código Eleitoral Brasileiro (1932), no seu artigo $2^{\mathrm{O}^{2}}$, fora considerado eleitor todo cidadão acima de 21 anos, sem qualquer distinção de sexo, inexistente, entretanto, a obrigatoriedade dos votos das mulheres e dos homens acima de 60 anos, de acordo com a previsão contida no artigo $121^{3}$ desse mesmo código.

Com a luta pela emancipação feminina ganhando força ao redor do Brasil, outras conquistas tornaram-se possíveis como, por exemplo, a de Carlota Pereira de Queiroz, única mulher na Assembleia Constituinte, e a primeira mulher a eleger-se para o cargo de deputada federal em 1934 (SCHUMAHER, 2015, p. 96-97), ano em que a nova Constituição (de 1934) previu o voto feminino, e serviu de cenário normativo para a eleição, no ano seguinte, de Antonieta de Barros, a primeira parlamentar negra do Brasil, em Santa Catarina. (SCHUMAHER, 2015, p. 95-96)

\footnotetext{
${ }^{2}$ Art. $2^{\underline{O}}$ É eleitor o cidadão maior de 21 anos, sem distinção de sexo, alistado na forma deste código.

${ }^{3}$ Art. 121. Os homens maiores de sessenta anos e as mulheres em qualquer idade podem isentar-se de qualquer obrigação ou serviço de natureza eleitoral.
}

Resenha Eleitoral (Florianópolis), v. 24, n. 2, p. 81-98, 2020 
Em 1986, Maria Luíza Fontenele tomou posse como a primeira mulher prefeita de uma capital brasileira (SCHUMAHER, 2015, p. 184185), e três anos depois, em 1989, Lívia Maria Pio realizou a primeira candidatura de uma mulher para a presidência da República do Brasil (Partido Nacional), porém, somente em 2011, uma mulher, Dilma Rousseff, foi eleita para o cargo. (SCHUMAHER, 2015, p. 386-391)

Ao longo dos anos, a partir da legislação eleitoral, observou-se um avanço na busca pela equidade no âmbito político e entre os seus instrumentos de efetivação, as ações afirmativas, que servem como mecanismos iniciais para que sejam superadas as desigualdades existentes, e minimizados os impactos danosos desse desnivelamento (também) político, não devendo ser concebidas como ferramentas-fim. Flávia Piovesan entende que as ações afirmativas:

Constituem medidas concretas que viabilizam o direito à igualdade, com a crença de que a igualdade deve se moldar no respeito à diferença e à diversidade. Através delas transita-se da igualdade formal para a igualdade material e substantiva (PIOVESAN, 2005, p. 49).

O objetivo de políticas públicas como a de cotas é a de promover a superação das desigualdades que marcam as sociedades oprimidas pelas estruturas machistas que a formam, e reparadas essas distorções as cotas tornam-se desnecessárias, respeitando-se a escolha política feita pelo Constituinte ao reconhecer a igualdade de todos, acompanhada, consequentemente, da representatividade plural e diversa, afinal, "os direitos não nascem todos de uma vez e nem de uma vez por todas" (BOBBIO, 2004, p. 9).

Em 1995, após o Brasil participar da IV Conferência Internacional sobre a Mulher em Pequim, foi promulgada a Lei 9.100 com o objetivo de regulamentar as eleições municipais de 1996, determinando que 20\% (vinte por cento) das vagas de cada partido ou coligação para o cargo de vereador (a) deveriam ser preenchidas por candidaturas de mulheres (artigo 11, $\int 3^{\circ}$ da Lei $9.100 / 95)^{4}$. Essa ação afirmativa, que buscava a maior participação da mulher na política municipal brasileira, encontrou imediata resistência com a criação da Lei Eleitoral 9.504/97, que determinou o aumento do

\footnotetext{
${ }^{4}$ Art. 11. Cada partido ou coligação poderá registrar candidatos para a Câmara Municipal até $125 \%$ (cento e vinte por cento) do número de lugares a preencher.

\ 3ำ 20\% (vinte por cento), no mínimo, das vagas de cada partido ou coligação deverão ser preenchidas por candidaturas de mulheres.
} 
número de vagas que cada partido ou coligação poderia lançar de forma que assim nenhum homem seria deslocado da disputa com a candidatura de mulheres, mitigados então os efeitos da medida adotada (artigo 10, caput e II da Lei 9.504)5: “... ou seja, nenhum homem sai para que as mulheres entrem, vamos, ao contrário, aumentar os espaços dos homens na política!” - provavelmente pensaram ao produzir o texto.

A lei eleitoral possuía um dispositivo transitório que definia um percentual de 25\% (vinte e cinco por cento) apenas para as eleições gerais de $1998^{6}$ e a partir de 2002, o artigo 10, \$ $3^{\circ}$ indicou que do número de vagas resultante das regras previstas, cada partido ou coligação deveria reservar o mínimo de 30\% (trinta por cento) e o máximo de 70\% (setenta por cento) para candidaturas de cada sexo, adotado nas eleições proporcionais para a composição das Câmaras de Vereadores, Assembleias Legislativas, Câmara Distrital e Câmara dos Deputados, de acordo com a votação de cada partido.

O sistema eleitoral, segundo Michael Gallagher e Paul Mitchell, é o que realiza uma conexão entre as preferências dos cidadãos e as decisões políticas dos governantes. Esse sistema irá estruturar um conjunto de regras que determinarão como os votos populares serão convertidos em assentos nas assembleias, ou seja, como será a composição do Parlamento (2005, p. 3).

O sistema eleitoral adotado num país pode exercer - e em verdade exerce - considerável influxo sobre a forma de governo, a organização partidária e a estrutura parlamentar, refletindo até certo ponto a índole das instituições e a orientação política do regime. (BONAVIDES, 2012, p. 265)

\footnotetext{
${ }^{5}$ Art.10. Cada partido poderá registrar candidatos para a Câmara dos Deputados, Câmara Legislativa, Assembleias Legislativas e Câmaras Municipais, até 150\% (cento e cinquenta por cento) do número de lugares a preencher.

II - nos municípios de até cem mil eleitores, nos quais cada coligação poderá registrar candidatos no total de até $200 \%$ (duzentos por cento) do número de lugares a preencher.

${ }^{6}$ Art. 80. Nas eleições a serem realizadas no ano de 1998, cada partido ou coligação deverá reservar, para candidatos de cada sexo, no mínimo, 25\% (vinte e cinco por cento) e, no máximo, $75 \%$ (setenta e cinco por cento) do número de candidaturas que puder registrar.
} 
O Código Eleitoral Brasileiro dispõe em seus artigos $106^{7}$ e $107^{8}$ como ocorrerá a contabilização dos votos e, de acordo com a reforma de 2015, com o advento da Lei 13.165, que mudou a redação do artigo $109^{9}$ do referido código, ficou estabelecida a exigência de um mínimo de votação nominal para os candidatos e candidatas, o que determina se irão ou não ocupar as cadeiras conquistadas pelos partidos/coligações, uma vez definido o quociente partidário.

A quantidade de votos obtida individualmente por um(a) candidato(a) não determina necessariamente a sua eleição no sistema proporcional, considerando que é imperioso que a votação recebida pelo partido político ultrapasse o quociente eleitoral. Uma vez estabelecida a quantidade de vagas a serem preenchidas, posterior ao quociente e às distribuições das sobras, serão definidos quais candidatos(as) serão eleitos(as), considerando a maior quantidade de votos nominais, geralmente, homens, portanto.

\section{O Legislativo do Estado do Pará, norte do Brasil: composição e produção legislativa}

O Brasil enfrenta sérias dificuldades na garantia e efetivação dos direitos fundamentais reconhecidos em nível constitucional. Além do recente processo de democratização, um dos fatores que dificultam que se desenvolva de forma igual é a extensão de seu território, sendo o quinto maior País do mundo. Dada essa dimensão territorial e a colonização dos índios nativos por diversos grupos étnicos acarretou em uma grande mis-

\footnotetext{
${ }^{7}$ Art. 106, Código Eleitoral - Determina-se o quociente eleitoral dividindo-se o número de votos válidos apurados pelo de lugares a preencher em cada circunscrição eleitoral, desprezada a fração se igual ou inferior a meio, equivalente a um, se superior.

${ }^{8}$ Art. 107, Código Eleitoral - Determina-se para cada partido ou coligação o quociente partidário, dividindo se pelo quociente eleitoral o número de votos válidos dados sob a mesma legenda ou coligação de legendas, desprezada a fração.

${ }^{9}$ Art. 109, Código Eleitoral - Os lugares não preenchidos com a aplicação dos quocientes partidários e em razão da exigência de votação nominal mínima a que se refere o artigo 108 serão distribuídos de acordo com as seguintes regras: I - dividir-se-á o número de votos válidos atribuídos a cada partido ou coligação pelo número de lugares definido para o partido pelo cálculo do quociente partidário do artigo 107, mais um, cabendo ao partido ou coligação que apresentar a maior média um dos lugares a preencher, desde que tenha candidato que atenda à exigência de votação nominal mínima; II - repetir-se-á a operação para cada um dos lugares a preencher; III - quando não houver mais partidos ou coligações com candidatos que atendam às duas exigências do inciso I, as cadeiras serão distribuídas aos partidos que apresentem as maiores médias.
} 
cigenação, sendo hoje, um país de território continental que abrange uma pluralidade de pessoas e realidades, marginalizadas na arena de debates e decisões políticas, apesar de constituírem subjetivamente a sociedade.

A Região Norte do Brasil é a maior região em termos territoriais, que historicamente serviu de polo de exploração de matéria prima, com suas riquezas extraídas sendo levadas para regiões que se encontravam em outro estágio, no processo de industrialização. É também a região brasileira mais invisibilizada, considerando que as dificuldades enfrentadas pelo país, como a democratização e efetivação de direitos fundamentais, deparam-se com obstáculos ainda maiores, considerando as peculiaridades do território que abriga 80\% (oitenta por cento) da Floresta Amazônica.

No que diz respeito aos direitos políticos, a "mini-reforma" política realizada em 2009, debatida anteriormente em nível nacional, mesmo com a indicação da obrigatoriedade do preenchimento das vagas das cotas, não provocou grandes mudanças concretas, visto que se trata apenas de uma questão de reserva de vagas à candidaturas. Em atenção à região Norte do Brasil, foi realizado um levantamento do resultado das eleições para os cargos de Deputado(as) Estaduais nos anos de 2010, 2014 e 2018, a partir de coleta de informações pesquisadas nos sites das Assembleias Legislativas, assim como o percentual de mulheres eleitas por partido nesse mesmo período.

A composição das Assembleias Legislativas da Região Norte ainda se mostra bastante precária no que diz respeito à representatividade feminina. As candidatas do gênero feminino sequer chegaram a alcançar $22 \%$ (vinte e dois por cento) dos assentos disponíveis nas eleições gerais de 2010, 2014 e 2018, conforme informações obtidas dos sites das Assembleias Legislativas dos Estados do Norte do Brasil, ainda que durante esses anos as legislações de incentivo tenham avançado, mesmo que minimamente.

Quando tratamos do papel dos partidos políticos na fomentação desta representatividade, ainda há muito a ser feito, visto que existem desafios consequentes da estrutura patriarcal de nossa sociedade a serem enfrentados também intrapartidariamente, o que dificulta que mulheres concorram aos assentos políticos em igualdade de condições.

Nas últimas três eleições gerais, os partidos políticos que mais elegeram mulheres para a composição das Assembleias Legislativas Estaduais, da Região Norte foram: PSB, PROS, PRB, PODEMOS, DEM (4,5\%); PT do B/AVANTE (6,1\%); PR, PP (7,6\%); PDT (9,1\%); PT (10,6\%); MDB $(16,7 \%)$ e PSDB (19,7\%). (conforme pesquisa realizada no site das Assembleias Estaduais). 
Em relação à composição das casas legislativas estaduais da Região Norte é possível observar que as reformas adotadas pela legislação eleitoral quanto ao incentivo da participação das mulheres na política, no exercício da sua capacidade eleitoral ativa, apesar de importantes, não trouxeram mudanças concretas significativas aos números a partir da obrigatoriedade das cotas de gênero com a reserva de candidaturas, ainda que tenham decorrido 10 anos, desde então.

Os maiores números de mulheres eleitas são de partidos de direita ou centro-direita, o que pode ser considerado como um empecilho na adoção de políticas feministas ou de debate de questões a partir da perspectiva de gênero, visto que a candidata deve seguir os ideais do partido como um todo, de forma que as algumas mulheres se apropriam da pauta feminista e acabam por "abandonar" posteriormente por conveniência partidária.

Considerando que o Brasil passou por mais de 20 anos de ditadura militar, apesar da Constituição de 1964 ter igualado o voto feminino ao voto masculino em termos de obrigatoriedade, o exercício desse direito ficou restringido durante a ditadura ${ }^{10}$, o que impossibilitou o lançamento de candidaturas para a construção de carreiras políticas. Na época, a proibição e a perseguição de movimentos e organizações que fizessem críticas ao governo costumavam desencorajar ainda mais, especialmente as mulheres, a atuação na política.

Por consequência, os partidos políticos dominantes nos assentos legislativos até os dias de hoje são aqueles que fizeram carreira durante a ditadura militar, que com suas ideologias conservadoras reproduzem um discurso relacionando a ordem política com a ordem familiar, envolta aos mandamentos católicos, adotando concepções religiosas sobre qual é o papel do homem e da mulher na sociedade, num afastamento da ideia de separação entre Igreja e Estado (BIROLI, 2018, p. 178).

Com o objetivo de evidenciar as desigualdades persistentes entre as mulheres que conseguiram ser inseridas nesse cenário político, o gráfico abaixo busca ampliar o debate, levando em conta quem são as mulheres que estão sendo eleitas nesse contexto, trazendo destaque para o estado civil e a identificação racial/étnica das candidatas eleitas na Região Norte.

${ }^{10}$ CÂMARA DOS DEPUTADOS. Anos 60 e 70: ditadura e bipartidarismo. 2008. Disponível em: <https://www.camara.leg.br>. Acesso em: nov. 2019. 
No Brasil, tivemos imigrações de diversos povos e etnias, de forma que a nossa leitura étnica/racial é baseada no fenótipo socialmente compreendido a partir de seus traços, sua pele, seu corpo e seu cabelo, o que torna a nomenclatura de raça confusa para muitos. A divisão de grupos étnicos/ raciais considerados com a coleta destes dados das deputadas estaduais eleitas na Região Norte foram: pardas, brancas, indígenas, negras.

\section{DADOS DAS DEPUTADAS ESTADUAIS DA REGIÃO NORTE}

\% referente as eleições de 2010, 2014 e 2018

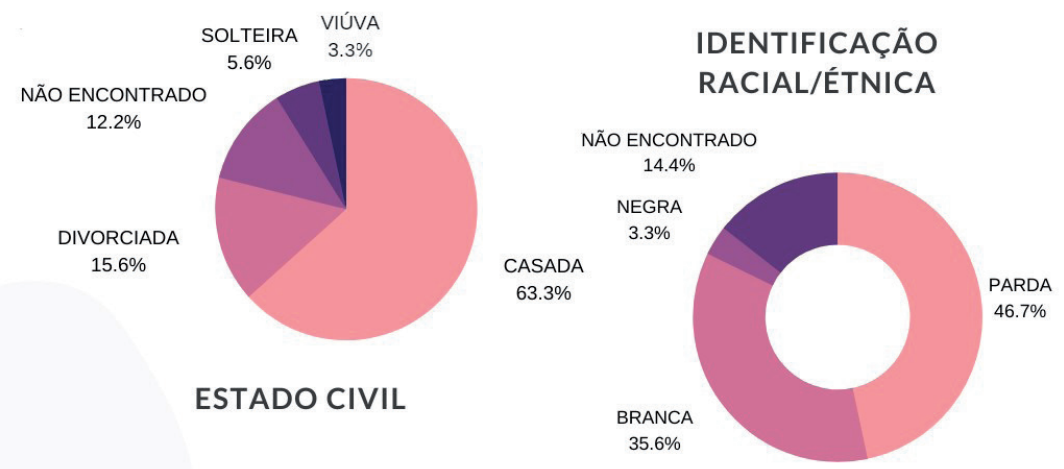

Fonte: Sites das Assembleias Legislativas Estaduais

Os dados acima se (com)provam importantes quando consideramos que nossa sociedade espera que as mulheres exerçam papéis de gêneros que, além de serem opressores, quando se aliam a indicadores sociais de classe e raça, agravam ainda mais essa desigualdade.

A divisão sexual do trabalho, por exemplo, é um dos fatores que tem grande impacto negativo na participação da mulher na política, uma vez que esta enfrenta como parte do dia a dia o trabalho não remunerado exercido dentro de casa, com ou sem filhos, num movimento constante que perfaz um "ciclo vicioso" marcado pela reprodução, e não apenas biológica.

Com a redemocratização, o debate sobre a presença - quase inexistente - de mulheres na política entrou em evidência. Atualmente, discute-se acerca da (in)suficiência do voto em mulheres independente das propostas ou interesses defendidos, estabelecendo um recorte quantitativo para o debate, a despeito da qualidade dessa representatividade. 
Votar em alguém do gênero feminino não é fator determinante para que a candidata defenda políticas feministas, porque o voto em mulheres nem sempre resulta em políticas em benefício delas próprias.

Ainda que não se deva esperar que mulheres eleitas venham a tratar apenas de assuntos relacionados à mulher, a participação ativa delas na política deve repercutir diretamente na produção legislativa em seu favor, considerando que diversos temas que buscam o bem-estar das mulheres, o alcance da igualdade de gêneros e a sua emancipação não tem sido prioridade para os homens e quando discutidos não consideram os estudos de gênero.

A eleição de mulheres que não defendem políticas feministas, mesmo trazendo um aumento na representatividade feminina não nos aproxima de uma igualdade de gênero no plano prático da vida em sociedade, visto que defendem ideais patriarcais. Contudo, não podemos esperar que sejam designadas a essas mulheres pastas que tratam apenas de assuntos específicos a elas, à família, às crianças e aos idosos, posto que essa ideia reforça ainda mais os papéis de gênero, que impõem à mulher o dever do cuidado, ignorando muitas das vezes sua formação profissional e especialização em outras áreas.

Para além disso, a socialização dos homens como sujeitos pertencentes aos espaços públicos impede que enxerguem os obstáculos que as mulheres enfrentam para sua inserção na política, dada a sua posição de privilégio. É imprescindível que ao eleger mulheres, as diversas pautas feministas, que são atribuídas incorretamente como de interesse exclusivo da mulher, - a exemplo dos direitos reprodutivos e sexuais, combate à violência contra as mulheres, assim como a ampliação da participação da mulher na política - recebam uma maior atenção.

A violência política de gênero contra a mulher é tal que, muitas que possuem uma carreira política no Brasil, não buscam sequer conhecer o feminismo por conta do estigma que essa luta política traz consigo, especialmente em razão da desinformação. Essas mulheres se ocupam de temas considerados de "menor prestígio" no campo político, reforçando os papéis tradicionais, e em busca da validação de seus discursos em alianças antifeministas.

A partir dos dados coletados para essa pesquisa foi possível perceber que o Pará foi o estado que atingiu nas Eleições Gerais de 2018, o maior 
número de representatividade feminina nas Assembleias Legislativas da Região Norte, inclusive se analisados os últimos 10 anos, com 31 homens e 10 mulheres ocupando os assentos do legislativo estadual. Considerando essa conquista significativa, mas ainda aquém do necessário para garantir a igualdade política, importante identificar as políticas públicas em favor da mulher que têm sido adotadas, na Assembleia Legislativa do Estado do Pará (Alepa), de 2009 a 2019.

Na última década, a Assembleia Legislativa do Estado do Pará, mesmo com o crescimento do número de mulheres ocupando os assentos, não tem se dedicado a aprovar legislações que adotam políticas públicas efetivas em relação à mulher, seja pela dificuldade de inserção de um maior número de mulheres na política, seja pelo esvaziamento da pauta feminista pelas mulheres que estão ocupando os espaços decisórios.

Em consulta à legislação no site da "Alepa", verificou-se que o Estado do Pará tem um considerável número de leis com o objetivo de conceder títulos e honrarias, além de reconhecer como de utilidade pública associações, projetos e coletivos de mulheres, com 15 leis com esse objetivo, de um total de 26 leis destinadas às mulheres, ou seja, mais que a metade das leis não toma qualquer providência ou produz efeitos materiais, repercutindo na desigualdade que nos assola.

Ao tornar a pesquisa mais específica, observarmos as legislações que tratam da saúde, que é um direito de todos(as) e dever do Estado (Constituição Federal, na Seção II do Título VIII - Da Ordem Social) ${ }^{11}$, inclusive, no que toca à aplicação de recursos em ações e serviços de saúde.

Conforme os dados coletados, entre os anos de 2009 e 2019, na "Alepa", apenas três leis foram promulgadas nesse período tratando sobre a saúde da mulher no Pará: Lei no 7.318/2009 que institui a semana estadual de prevenção ao HPV e ao combate ao câncer do colo do útero; Lei $\mathrm{n}^{\circ}$ 7.613/2012 que garante o direito de amamentação nos concursos públicos estaduais; e Lei no 7.945/2014 que cria a Política de Saúde da Mulher Detenta.

Essas legislações analisadas, apesar de possuírem conteúdo relevante, não se mostram suficientes para a garantia de direitos fundamentais. O caso mais recente a ter visibilidade nacional foi quando a força-tarefa de

${ }^{11}$ Artigo 196, CF - A saúde é direito de todos e dever do Estado, garantido mediante políticas sociais e econômicas que visem à redução do risco de doença e de outros agravos e ao acesso universal e igualitário às ações e aos serviços para sua promoção, proteção e recuperação.

Resenha Eleitoral (Florianópolis), v. 24, n. 2, p. 81-98, 2020 
intervenção penitenciária foi acusada pelas detentas do Centro de Reeducação Feminino de Ananindeua de "terem sido espancadas e obrigadas a sentarem apenas de calcinha em cima de um formigueiro" conforme os vídeos divulgados (The Intercept Brasil, 2019). Para além do descumprimento de uma lei estadual, a Lei 7.945/14 - e inequivocamente da Constituição Federal que busca garantir a saúde das detentas, essa prática configura violação grave de direitos humanos a partir de uma ação do Poder Executivo estadual em conjunto com órgãos de fiscalização do sistema prisional federal.

Em análise da redação de outras legislações, é possível observar que em sua grande maioria tratam dos direitos das mulheres quando estas exercem papéis de gênero esperados pela sociedade como a figura de "mãe", por exemplo, o direito de amamentar ao prestar um concurso público (Lei n⿳ 7.613, de 02 de abril de 2012). São garantias fundamentais que sequer deveriam ser questionadas, necessitando ainda menos de lei para assegurá-las, entretanto, esta é a realidade do acesso aos direitos básicos que a mulher enfrenta diariamente.

\section{Conclusão}

Os dados levantados em relação ao Estado do Pará, da Região Norte do Brasil, nos apresentam um longo caminho a ser percorrido na luta pela igualdade e na promoção do papel da mulher na política, uma vez que se trata de uma região invisibilizada, carente de políticas públicas e com dificuldades únicas quando se trata de um processo eleitoral acessível e que represente a todos os grupos que formam o núcleo social, até mesmo aqueles específicos dessa região, como dos indígenas e quilombolas, por exemplo.

A produção de legislação em favor das mulheres nas casas legislativas estaduais da região norte, apesar de existente, ainda se mostra substancialmente rasa, pois a maior parte dessa produção ainda não corresponde à instituição de políticas públicas que, além de partirem das reais necessidades e aplicáveis no plano prático, precisam combater os conceitos patriarcais e estruturas de opressão, nos quais nossa sociedade está fundada.

É a partir do feminismo que passamos a observar de forma crítica o espaço que é cedido às mulheres na sociedade e esse criticismo é o que permite que passemos a lutar para conquistar outros espaços em busca não apenas de emancipação própria, mas de todas as mulheres. Para que pautas feministas sejam levadas em consideração é necessário que a sociedade 
como um todo permaneça atenta aos pleitos eleitorais, destinando seu voto a uma candidata, que se comprometa com os temas que importam para cada um de nós e que trarão mudanças concretas no cenário de desigualdade que vivemos.

Portanto, após o estudo do conteúdo é necessário afirmar que, ainda que tenham sido conquistados avanços legislativos que aumentaram a participação da mulher na política, a reserva de cotas não se mostrou suficiente para alcançar a tão almejada equidade, tornando imprescindível que passe a ser discutida e adotada a paridade de cadeiras parlamentares igualmente entre gêneros.

É necessário exigir do Poder Legislativo uma reforma completa das regras eleitorais de modo a minimizar as desigualdades abissais que corroem a política em nossa sociedade historicamente, e que possamos gozar de um sistema eleitoral que não seja prejudicial à eleição de pessoas que fazem parte de grupos que, apesar de numericamente majoritário se encontram à margem em termos de representatividade, como é o caso das mulheres, devendo abarcar de forma ampla mulheres negras, indígenas, pertencentes à comunidade LGBTQI+, ou seja, não podemos separar os indicadores sociais e étnico/raciais desta luta.

\section{Referências}

ADICHIE, Chimamanda Ngozi. Sejamos todos feministas. 1 ed., São Paulo: Companhia das Letras, 2015.

BARROSO, Luis Roberto. Constituição, Democracia e Supremacia Judicial: direito e política no Brasil contemporâneo. Revista de Direito do Estado, n.16, 2009.

BEAUVOIR, Simone de. O segundo Sexo: Fatos e Mitos. 2 ed., Rio de Janeiro: Ed. Nova Fronteira, 1980.

BIROLI, Flávia. Gênero e Desigualdades: os limites da Democracia no Brasil. 1ed., São Paulo: Boitempo, 2018.

BOBBIO, Norberto. A era dos direitos. Trad. Carlos Nelson Coutinho. Apresentação de Celso Lafer. Nova ed. Rio de Janeiro: Elsevier, 2004. $7^{\mathrm{a}}$ reimpressão. 
BRUGGER, Andrey da Silva. Judicialização da vida: o cenário das mulheres e breves anotações sobre supremacia judicial e supremacia constitucional. $\mathbf{O}$ Social em Questão, v. 31, p. 73-92, 2014.

CÂMARA DOS DEPUTADOS. Anos 60 e 70: ditadura e bipartidarismo. 2008. Disponível em: < https://www.camara.leg.br/noticias/122463-anos-60-e-70-ditadura-e-bipartidarismo/>. Acesso em: nov.2019.

FÓRUM. Bancada feminina quer cota de $\mathbf{3 0} \%$ das cadeiras do Congresso para mulheres. Disponível em: < https://revistaforum.com.br/ noticias/bancada-feminina-quer-cota-de-30-das-cadeiras-congresso-para-mulheres/>. Acesso em: nov. 2019.

GALLAGHER, Michael; MITCHELL, Paul (Ed.). The politics of electoral systems. Oxford: Oxford University Press, 2005.

HABERMAS, Jürgen. Direito e Democracia: entre facticidade e validade. São Paulo: Tempo Brasileiro, 1997. v. 1 (Coleção Biblioteca Tempo Universitário, n. 101) apud AQUINO, Jorge Inácio de. O Direito e sua interpretação na atualidade. Disponível em < http://jus2.uol.com.br/doutrina/texto. asp?id=11415\&amp;amp;p=2\&amp;gt; > . Acesso em: 05 set. 2019.

LIMA, Leonardo Duncan Moreira. Stare Decisis e Súmula Vinculante: um estudo comparado. Revista Direito, Estado e Sociedade, [PUCRIO], Rio de Janeiro, n. 14, 1999.

MORO diz que não há tortura em presídios no Pará. Presas obrigadas a sentar em formigueiro discordam. The Intercept Brasil. Disponível em: $<$ https://theintercept.com /2019/10/08/presas-forca-tarefa-moro-tortura/>. Acesso em: 20 jan. 2020.

NETTO, Ernesto. A influência da jurisprudência no direito brasileiro. Disponível em:; < https://www.direitonet.com.br/artigos/exibir/5872/A-influencia-da-jurisprudencia-no-direito-brasileiro-Parte-I >. Acesso em: 10 set. 2019.

PINHEIRO, Celia Regina de Lima; SALES, José Edvaldo Pereira; FREITAS, Juliana Rodrigues (Coord.). Constituição e processo eleitoral. Belo Horizonte: Fórum, 2018. 406 p.

PIOVESAN, Flávia. Ações afirmativas e direitos humanos. Revista USP, n. 69, p. 36-43, 1 maio 2006.

PIOVESAN, Flávia. Cadernos de Pesquisa, v. 35, n. 124, p. 43-55, jan./abr. 2005. 
PORTO, Walter Costa. Dicionário do voto. Brasília: UnB, 2000. p. 427-436. SCHUMAHER, SCHUMA. Mulheres no poder: trajetória na política a partir da luta das sufragistas do Brasil. 1 ed., Rio de Janeiro: Edições de Janeiro, 2015.

VOTO da Mulher. Tribunal Superior Eleitoral. Disponível em: <http:/ / www.tse.jus.br /eleitor/glossario/termos/voto-da-mulher>. Acesso em: 04 out. 2019.

Juliana Rodrigues Freitas - Doutora em Direito (2010 - UFPA/ Università di Pisa - Itália). Mestre em Direitos Humanos (2003 - UFPA). Pós-graduada em Direito do Estado (2006 - Universidade Carlos III de Madri - Espanha). Professora da Graduação e Mestrado em Direito do Centro Universitário do Estado do Pará (Cesupa). Pesquisadora do Observatório de Direito Eleitoral do CNPQ, promovido pela Universidade do Estado do Rio de Janeiro (UERJ). Presidente da Comissão da Mulher Advogada OAB/PA (2018). Conselheira Seccional OAB/PA (2019-2021). Membra Consultora da Comissão Especial de Estudo da Reforma Política (OAB-Federal). Membra Fundadora da Academia Brasileira de Direito Eleitoral e Político (Abradep).

Laís Vieira Guimarães - Graduanda do curso de Direito no Centro Universitário do Pará (Cesupa). Bolsista do Programa de Iniciação Científica e Tecnológica do Cesupa (Pibict,2019). 
